\title{
Factors Associated With Renal and Urological Complications in Patients Suffering From Spinal Cord Injuries During Subsequent Years of Post-Injury
}

\author{
Banafshe Dormanesh ${ }^{1, *}$, Mohammad Khak $^{1,2}$, Vafa Rahimimovaghar ${ }^{3}$ \\ ${ }^{1}$ AJA University of Medical Sciences, Tehran, IR Iran \\ ${ }_{3}^{2}$ Tehran University of Medical Sciences, Tehran, IR Iran \\ ${ }^{3}$ Sina Trauma and Surgery Research Center (STSRC), Department of Neurosurgery, Tehran University of Medical Sciences, Tehran, IR Iran \\ *Corresponding author: Banafshe Dormanesh, AJA University of Medical Sciences, Tehran, IR Iran. Tel: +98-2188028935, E-mail: dormanesh68@yahoo.com .
}

Received: September 18, 2013; Revised: October 1, 2013; Accepted: October 5, 2013

Background: Renal and urological complications are the main causes of mortality and morbidity associated with spinal cord injury(SCI). Besides clinical risk factors, there are environmental predisposing factors making a patient prone to develop any complications.

Objectives: The present study aimed to evaluate the risk factors of developing nephrolithiasis, urinary tract infection, hydronephrosis and renal failure, as the main renal and urological complications in the SCI patients.

Materials and Methods: The database of SCI patients of State Welfare Organization of Iran (SWOI) was used for data gathering. The data were collected between 2008 and 2010 by 222 separate teams consisting of 6 mobile rehabilitation team members. The independent risk factors of developing nephrolithiasis, urinary tract infection, hydronephrosis and renal failure were recognized by controlling the confounders after entering all biologically plausible variables in multivariate regression models.

Results: Complete information was available for 5901 (72.59\%) of the patients. Urologic and renal complications were reported in 2358 (40\%) of the patients among which $286(4.8 \%)$ had chronic renal failure, $127(2.2 \%)$ from hydronephrosis,307 (5.2\%) from nephrolithiasis and 2138 (36.2\%) from urinary tract infection. Generally, renal and urological complications associated with old age, and more time since SCI; however, lumbar level of injury and living in rural area negatively correlated with renal and urological complications.

Conclusions: SCI patients with and without renal and urological complications are different regarding demographic and environmental factors; hence, it is necessary to determine the modifiable risk factors in to design preventive programs.

Keywords: Spinal Cord Injuries; Kidney Diseases; Urologic Diseases

\section{Background}

Spinal cord injury (SCI) is a disabling condition with an annual incidence of 11000 per year in the United States $(1,2)$. The injury may lead to a group of primary and secondary complications such as sensory, motor and autonomic disorders, immobility, neurogenic bladder and bowel dysfunction $(3,4)$. The secondary complications following SCI may be lifelong injuries and are the leading causes of morbidity and mortality among the patients with SCI. These complications impose a high cost to the patient and the healthcare system resulting in significant decrease in the patient's quality of life $(5,6)$. Renal and urological complications are among the secondary complications and main causes of morbidity and mortality in SCI patients $(1,7)$.

It is estimated that about $8 \%$ of patients with SCI experience an episode of nephrolithiasis during their life (8) with an increased incidence during the first three months after SCI (3). Development of nephrolithiasis results in urinary stasis and ultimately bacterial overgrowth and urinary infection. Hence, the bacteria move from the distal parts to the sterile proximal ducts. Furthermore, the obstruction resulted from nephrolithiasis can cause urinary reflux from bladder to the ureters and finally pyelocaliceal system leading to hydronephrosis (9). If not treated, any of the three above mentioned complications might result in renal failure.

\section{Objectives}

Although timely diagnosis and treatment of these complications ar important, an early diagnosis in SCI patients is difficult due to impaired sensorineural function. Although there are many clinical risk factors for renal and urological complications in SCI patients, the results in different studies are controversial. Besides, there are environmental predisposing factors that make a patient prone to develop any complications. As a result, the present study aimed to evaluate the risk factors for developurological complications of spinal cord injuries.

Copyright $(C)$ 2013, AJA University of Medical Sciences. This is an open-access article distributed under the terms of the Creative Commons Attribution License, which permits unrestricted use, distribution, and reproduction in any medium, provided the original work is properly cited. 
ing nephrolithiasis, urinary infection, hydronephrosis and renal failure in the SCI patients under the coverage of State Welfare Organization of Iran.

\section{Materials and Methods}

The study protocol was approved by the ethics committee of Sina Trauma and Surgery Research Center, Tehran University of Medical Sciences. The database of SCI patients of State Welfare Organization of Iran (SWOI) was used for data gathering. SWOI provides social, financial, medical, and rehabilitative supports for disabled people primarily in low socioeconomic classes, after confirmation of the presence of the disability (here as SCI) by the medical care providers of the organization.

The data were collected between 2008 and 2010 by 222 separate teams consisting of 6 mobile rehabilitation team members including a physiotherapist, a general practitioner, a psychologist, an occupational therapist, a social worker, and a nurse. A detailed questionnaire was filled by the trained members of the mobile rehabilitation team who personally examined all patients and took a relevant history. The questionnaire included the information on sex, age, age at SCI, time since SCI, level of injury, educational level, occupational status, living place, marital status, having a caregiver and type of injury (traumatic or non-traumatic). Pertinent laboratory tests and advanced imaging studies were collected where necessary. In each city, a neurosurgeon or an orthopedic surgeon confirmed the diagnosis of SCI in the individuals and the diagnosis and treatment of renal and urological complications including chronic renal failure, hydronephrosis, nephrolithiasis and urinary tract infection were performed by an internist.

SPSS software version 16.00 (SPSS Inc., Chicago, IL) was employed to perform statistical analysis. KolmogorovSmirnov test was used to check normal distribution of the ordinal variables, as well as the variables among time intervals as they were recorded in an ordered scale. Univariate analysis and chi-square test were used to identify the primary risk factors of renal and urological complications. Then, in 5 multivariate regression models, the independent risk factors of renal or urological complications, chronic renal failure, hydronephrosis, nephrolithiasis and urinary tract infection were recognized by controlling the confounders after entering all biologically plausible variables with a P-value less than 0.1 in univariate analysis and removing them in a backward process.

\section{Results}

A total of 8129 SCI patients included in the database; however, the data for 2228 (27.41\%) patients were incomplete, remaining 5901 cases for the final analysis. Traumatic SCI was the main cause of disability in 3664 (62.1\%) patients; the etiologies of the non-traumatic SCI are presented in Table 1. Urologic and renal complications were reported in 2358 (40\%) of the patients among, which 1522 (64.5\%) had traumatic SCI. The causes of URCs included CRF in 286 (4.8\%), hydronephrosis in 127 (2.2\%), nephrolithiasis in 307 (5.2\%), and UTI in 2138 (36.2\%) of the patients.

\begin{tabular}{|c|c|c|c|}
\hline Cause & Total, No. $(\%)(\mathbf{n}=2237)^{a}$ & With URC $^{\mathrm{b}}$, No. $(\%)(\mathbf{n}=\mathbf{8 3 6})^{\mathrm{c}}$ & Without URC, No. $(\%)(n=1401)^{\mathrm{C}}$ \\
\hline Congenital & $868(38.8)$ & $327(39.11)$ & $541(38.62)$ \\
\hline Tumor & 267 (11.9) & $106(12.68)$ & $161(11.49)$ \\
\hline Infection & $128(5.7)$ & $64(7.66)$ & $64(4.57)$ \\
\hline Canal stenosis & $116(5.2)$ & $45(5.38)$ & $71(5.07)$ \\
\hline Genetic disorders & $111(5.0)$ & $32(3.83)$ & $79(5.64)$ \\
\hline Iatrogenic & $69(3.1)$ & $28(3.35)$ & $41(2.93)$ \\
\hline Scoliosis & $69(3.1)$ & $23(2.75)$ & $46(3.28)$ \\
\hline Other & $609(27.2)$ & $211(25.24)$ & $398(28.41)$ \\
\hline
\end{tabular}

\footnotetext{
a The percentages are reported considering the total number of patients with SCI as the denominator.

b Abbreviations: URC; urological and renal complications.

${ }^{\mathrm{C}}$ The percentages are reported considering the total number of each cause as the denominator.
}

Univariate regression analysis revealed that presence of URCs was associated with age, age at SCI, time since SCI, living place, level of injury and type of injury. Besides, such association was observed between CRF and age, time since SCI, having a caregiver at home and type of injury, between hydronephrosis and age at SCI, education level and marital status, between nephrolithiasis and sex, age, age at SCI, time since SCI and level of injury, and between UTI and age, age at SCI, level of injury, living place, having a caregiver at home and type of injury (Table 2 ). 
Dormanesh B et al.

\begin{tabular}{|c|c|c|c|c|c|c|}
\hline Variable & $\begin{array}{l}\operatorname{RUC}^{\mathrm{a}}(\mathbf{n}=\mathbf{2 3 5 8}), \\
\text { No. }(\%)\end{array}$ & $\begin{array}{l}\operatorname{CRF}^{\mathrm{a}}(\mathbf{n}=\mathbf{2 8 6}), \\
\text { No. }(\%)\end{array}$ & $\begin{array}{l}\mathbf{H N}^{\mathrm{a}}(\mathbf{n}=127), \\
\text { No. }(\%)\end{array}$ & $\begin{array}{l}\text { NL }^{\mathrm{a}}(\mathbf{n}=307) \\
\text { No. }(\%)\end{array}$ & $\begin{array}{l}\mathrm{UTI}^{\mathrm{a}}(\mathbf{n}= \\
2138), \text { No. (\%) }\end{array}$ & $\begin{array}{l}\text { Total }(\mathbf{n}=) \text {, } \\
\text { No. }(\%)\end{array}$ \\
\hline \multicolumn{7}{|l|}{ Sex } \\
\hline Female & $643(39.14)$ & $81(4.93)$ & $38(2.31)$ & $63(3.83)$ & $582(35.42)$ & $1643(100)$ \\
\hline Male & $1715(40.28)$ & $205(4.81)$ & 89 (2.09) & $244^{\mathrm{b}}(5.73)$ & $1556(36.54)$ & $4258(100)$ \\
\hline \multicolumn{7}{|l|}{ Age, $y$} \\
\hline$\geq 10$ & $148(29.54)$ & $14(2.79)$ & $11(2.20)$ & $9(1.80)$ & $139(27.74)$ & $501(100)$ \\
\hline $11-20$ & $296^{\mathrm{b}}(40.88)$ & $32(4.42)$ & $18(2.49)$ & $35^{\mathrm{b}}(4.83)$ & $270^{\mathrm{b}}(37.29)$ & $724(100)$ \\
\hline $21-50$ & $1532^{\mathrm{b}}(40.88)$ & $187^{\mathrm{b}}(4.99)$ & $79(2.11)$ & $214^{\mathrm{b}}(5.71)$ & $1382^{\mathrm{b}}(36.87)$ & $3748(100)$ \\
\hline$>50$ & $382^{\mathrm{b}}(41.16)$ & $53^{\mathrm{b}}(5.71)$ & $19(2.05)$ & $49^{\mathrm{b}}(5.28)$ & $347^{\mathrm{b}}(37.39)$ & $928(100)$ \\
\hline \multicolumn{7}{|l|}{ Age at SCI, y } \\
\hline $0-1$ & $398(36.18)$ & $44(4.0)$ & $30(2.73)$ & $42(3.82)$ & $371(33.73)$ & $1100(100)$ \\
\hline $2-20$ & $582^{\mathrm{b}}(42.45)$ & $75(5.47)$ & $40(2.92)$ & $83^{\mathrm{b}}(6.05)$ & $517^{\mathrm{b}}(37.71)$ & $1371(100)$ \\
\hline$>20$ & $1378^{\mathrm{b}}(40.17)$ & $167(4.87)$ & $57^{\mathrm{C}}(1.66)$ & $182^{\mathrm{b}}(5.31)$ & $1250(36.44)$ & $3430(100)$ \\
\hline \multicolumn{7}{|l|}{ Time since SCI, y } \\
\hline$<1$ & $273(37.50)$ & $19(2.61 \%)$ & $10(1.37)$ & $17(2.34)$ & $250(34.34)$ & $728(100)$ \\
\hline $1-5$ & $691(37.01)$ & $75(4.02 \%)$ & $37(1.98)$ & $68(3.64)$ & $631(33.80 \%)$ & $1867(100)$ \\
\hline$<5$ & $1394^{\mathrm{b}}(42.17)$ & $192^{\mathrm{b}}(5.81)$ & $80(2.42)$ & $222^{\mathrm{b}}(6.72)$ & $1257(38.02)$ & $3306(100)$ \\
\hline \multicolumn{7}{|l|}{ Level of injury } \\
\hline Cervical & $418(42.14)$ & $49(4.94)$ & $17(1.71)$ & $62(6.25)$ & $373(37.60)$ & $992(100)$ \\
\hline Thoracic & $626(45.0)$ & $54(3.88)$ & $36(2.59)$ & $82(5.90)$ & $585^{\mathrm{b}}(42.06)$ & $1391(100)$ \\
\hline Lumbar & $1314^{\mathrm{C}}(37.35)$ & $183(5.20)$ & $74(2.10)$ & $163^{\mathrm{C}}(4.63)$ & $1180^{C}(33.54)$ & $3518(100)$ \\
\hline \multicolumn{7}{|l|}{ Education level } \\
\hline$<$ High school & $1668(39.75)$ & $205(4.89)$ & $83(1.98)$ & $220(5.24)$ & $1527(36.39)$ & $4196(100)$ \\
\hline High school/college & $602(41.29)$ & $74(5.08)$ & $43^{\mathrm{b}}(2.95)$ & $74(5.08)$ & $535(36.69)$ & $1458(100)$ \\
\hline$\geq$ Bachelor's degree & $88(35.63)$ & $7(2.83)$ & $1(0.40)$ & $13(5.26)$ & $76(30.77)$ & $247(100)$ \\
\hline \multicolumn{7}{|l|}{ Occupational status } \\
\hline Employed & $192(42.29)$ & $23(5.07)$ & $8(1.76)$ & $32(7.05)$ & $168(37.0)$ & $454(100)$ \\
\hline Retired & $100(47.85)$ & $10(4.78)$ & $7(3.35)$ & $13(6.22)$ & $90(43.06)$ & $209(100)$ \\
\hline Unemployed & $2066(39.44)$ & $253(4.83)$ & $112(2.14)$ & $262(5.0)$ & $1880(35.89)$ & $5238(100)$ \\
\hline \multicolumn{7}{|l|}{ Living place } \\
\hline Urban & $1806(41.01)$ & $210(4.77)$ & $96(2.18)$ & $219(4.97)$ & $1636(37.15)$ & $4404(100)$ \\
\hline Rural & $552^{\mathrm{C}}(36.87)$ & $76(5.08)$ & $31(2.07)$ & $88(5.88)$ & $502^{\mathrm{C}}(33.53)$ & $1497(100)$ \\
\hline \multicolumn{7}{|l|}{ Marital status } \\
\hline Married & $1188(39.13)$ & $146(4.81)$ & $48(1.58)$ & $161(5.30)$ & $1066(35.11)$ & $3036(100)$ \\
\hline Single & $1170(40.85)$ & $140(4.89)$ & $79^{\mathrm{b}}(2.76)$ & $146(5.10)$ & $1072(37.43)$ & $2864(100)$ \\
\hline \multicolumn{7}{|l|}{ Caregiver at home } \\
\hline Yes & $2178(40.30)$ & $249(4.61)$ & $119(2.20)$ & $279(5.16)$ & $1987(36.76)$ & $5405^{\mathrm{b}}(100)$ \\
\hline No & $180(36.29)$ & $37^{\mathrm{b}}(7.46)$ & $8(1.61)$ & $28(5.65)$ & $151^{\mathrm{C}}(30.44)$ & $496(100)$ \\
\hline \multicolumn{7}{|l|}{ Type of injury } \\
\hline Traumatic & $836(37.37)$ & $127(5.68)$ & $49(2.19)$ & $104(4.65)$ & $749(33.48)$ & $2237(100)$ \\
\hline Non-traumatic & $1522^{\mathrm{b}}(41.54)$ & $159^{\mathrm{C}}(4.34)$ & $78(2.13)$ & $203(5.54)$ & $1389^{\mathrm{b}}(37.91)$ & $3664(100)$ \\
\hline
\end{tabular}

\footnotetext{
a Abbreviations: RUC, renal and urological complications; CRF, chronic renal failure; HN, hydronephrosis; NL, nephrolithiasis; UTI, urinary tract infection.

${ }^{\mathrm{b}}$ Significantly higher in frequency than the first group; $\mathrm{P}$ value $<0.05$

${ }^{\mathrm{C}}$ Significantly lower in frequency than the first group; P value $<0.05$.
} 
The results of multivariate regression analysis are shown in Tables 3, 4, 5, 6 and 7.

Table 3. Risk Factors of Renal and Urological Complications in Patients With Spinal Cord Injury.

\begin{tabular}{lll}
\hline Risk Factor & Odds Ratio & Pvalue \\
\hline Age, $\mathbf{y}$ & & \\
$11-20$ & 1.53 & 0.001 \\
\hline $21-50$ & 1.51 & 0.001 \\
$>50$ & 1.48 & 0.001 \\
\hline Time since SCI ${ }^{\mathrm{a}}$ : $\mathbf{5}$ years & 1.27 & 0.006 \\
\hline Level of injury: lumbar & 0.83 & 0.013 \\
\hline Living place: rural & 0.85 & 0.010 \\
\hline
\end{tabular}

a Abbreviation: SCI; spinal cord injury.

Table 4. Risk Factors of Chronic Renal Failure in Patients With Spinal Cord Injury.

\begin{tabular}{lll}
\hline Risk Factor & Odds Ratio & Pvalue \\
\hline Age at SCI $^{\mathrm{a}}$ & & \\
1-20 years & 1.81 & 0.004 \\
\hline 20 years & 1.74 & 0.005 \\
\hline Time since SCI: > 5 years & 2.18 & 0.002 \\
\hline No caregiver at home & 1.53 & 0.021 \\
\hline Non-traumatic SCI & 0.65 & 0.002 \\
\hline
\end{tabular}

${ }^{a}$ Abbreviation: SCI, spinal cord injury.

Table 5. Risk Factors of Hydronephrosis in Patients With Spinal Cord Injury.

\begin{tabular}{lll}
\hline Risk Factor & Odds Ratio & P value \\
\hline Age at $\mathrm{SCI}^{\mathrm{a}}:>20$ years & 0.59 & 0.021 \\
$\begin{array}{l}\text { Education level: high school/ } \\
\text { college }\end{array}$ & 1.51 & 0.034 \\
\hline
\end{tabular}

${ }^{\mathrm{a}}$ Abbreviation: SCI, spinal cord injury.

Table 6. Risk Factors of Nephrolithiasis in Patients With Spinal Cord Injury.

\begin{tabular}{|c|c|c|}
\hline Risk Factor & Odds Ratio & Pvalue \\
\hline Female sex & 1.48 & 0.008 \\
\hline \multicolumn{3}{|l|}{ Age, $y$} \\
\hline $11-20$ & 2.28 & 0.031 \\
\hline $21-50$ & 2.57 & 0.007 \\
\hline$>50$ & 2.11 & 0.045 \\
\hline Time since $\mathrm{SCI}^{\mathrm{a}}:$ > 5 years & 3.30 & $<0.001$ \\
\hline Level of injury: lumbar & 0.71 & 0.028 \\
\hline
\end{tabular}

${ }^{\mathrm{a}}$ Abbreviation: SCI, spinal cord injury.
Table 7. Risk Factors of Urinary Tract Infection in Patients With Spinal Cord Injury.

\begin{tabular}{|lll|}
\hline Risk Factor & Odds Ratio & Pvalue \\
\hline Age, $\mathbf{y}$ & & \\
$11-20$ & 1.43 & 0.007 \\
\hline $21-50$ & 1.37 & 0.007 \\
\hline$>50$ & 1.33 & 0.029 \\
\hline Time since SCI ${ }^{\mathrm{a}} \mathbf{>}$ 5 years & 1.25 & 0.010 \\
\hline Level of injury & & \\
\hline $\begin{array}{l}\text { Thoracic } \\
\text { Lumbar }\end{array}$ & 1.19 & 0.043 \\
\hline $\begin{array}{l}\text { Education level: } \geq \text { bachelor's } \\
\text { degree }\end{array}$ & 0.85 & 0.030 \\
\hline $\begin{array}{l}\text { Living place: rural } \\
\text { No caregiver at home }\end{array}$ & 0.67 & 0.005 \\
\hline
\end{tabular}

a Abbreviation: SCI, spinal cord injury

\section{Discussion}

In the present study, the renal and urological complications and the associated factors were evaluated in the patients with SCI. Renal and urological complications including chronic renal failure (4.8\%), hydronephrosis (2.2\%), nephrolithiasis (5.2\%), and urinary tract infection (36.2\%) were present in $40 \%$ of the patients. Older age, disability duration more than 5 years, level of injury at lumbar spine and living in rural area were found as the risk factors for development of renal and urological complications. Regarding each of the complications individually, chronic renal failure was directly associated with older age, disability duration more than 5 years and lack of caregiver at home; however, traumatic SCI was associated with reduced risk of renal and urological complications. Moreover, hydronephrosis had a significant positive correlation with age at SCI more than 20 years and educational level higher than high school/college. There was a significantly higher risk of having renal stone among the females, the elderly and those with longer disability duration while SCI level at lumbar spine was associated with a lower risk of nephrolithiasis. Considering UTI, a significantly positive correlation was observed between UTI and old age, longer disability duration and SCI level at thoracic spine. However, educational level $\geq$ bachelor's degree, SCI level at lumbar spine, living in rural area and lack of a caregiver at home were negatively associated with UTI.

Patients with SCI are at higher risk of developing systemic infections due to their neurological condition. UTI is the most common urological complication in these patients, frequently leading to sepsis, hospitalization and mortality $(10,11)$. The prevalence of UTI in the present 
study was estimated to be $36.2 \%$ generally. The estimated prevalence is significantly higher than that of general population which is reported to be from $1 \%$ in school-aged girls to more than $20 \%$ in females older than 80 and $1-7 \%$ among the males $(12,13)$; UTI prevalence among females between 16 to 35 years old is approximately $10 \%$ annually with a life-long risk of $60 \%(14,15)$ and in males older than 75 years is between $7 \%-10 \%$ (16). In the present study, gender was not a risk factor for UTI. One of the main causes of lower UTI prevalence among males in general population compared with females is longer urethral length in men; however, urethra loses its protective effect in SCI patients due to frequent catheterization which can explain the equal UTI prevalence among males and females in this study. As in this study, old age is also associated with an increased risk of developing UTI in general population. Since SCI patients with long-term catheterization are prone to bacterial colonization in their urinary tracts, longer disability duration is also associated with higher risk of developing UTI. Among all levels of SCI, the highest risk of developing urinary disorders is in cervical and thoracic spine injuries as in these levels of injury, bladder is dyssynergic (17) and the uncontrolled detrusor contraction results in a high internal pressure in the bladder (18). Furthermore, patients with SCI level at cervical spine are more dependent than others in performing their daily activities resulting in a less attention to their personal health. Therefore, intestinal bacterial flora overgrows on their skin migrating to urinary tract and bladder; this shows the necessity of educating patients with more disability to reduce infection expansion. Simple educations such as hand washing by the caregivers before assisting the SCI patient has been mentioned by Esclarín (19) as an effective method in preventing infections. In addition, Stamm introduced periodic training of the hospital staff as an effective method in preventing UTI (20). Higher risk of UTI was observed when intermittent catheterization was personal by a nurse at home compared to personal catheterization (21); this could be attributed to the patient's more attention to his or her personal health.

Vesicourethral sphincter dysfunction occurs due to high pressure in bladder and recurrent UTI. Incomplete bladder emptying results in urinary retention as a nucleus for infection and stone. Moreover, low bladder capacity and dysfunction of the outer sphincter lead to urine stasis and higher pressure of the detrusor muscle during bladder filling $(22,23)$; these results in urinary reflux and dilatation of the ureters and finally renal pelvis which is called hydronephrosis. In the present study, the prevalence of hydronephrosis was $2.2 \%$. The prevalence of vesicoureteral reflux in SCI patients has been estimated as $17 \%$ to $25 \%(24,25)$. The real prevalence of hydronephrosis among SCI patients might be higher than the estimated amount in the present study because we evaluated the patients' medical records retrospectively and only the symptomatic patients treated for hydronephrosis were identified. This complication was positively associated with age at SCI, more than 20 years old, which is consistent with the study by McKinley reporting higher prevalence of hydronephrosis in the patients older than 60 years compared to those younger than 40 years (26). Lower educational level is associated with reduced attention to personal health which justifies the positive association between hydronephrosis and lower educational level in the present study.

Persistent injury to the urinary system by untreated UTI and hydronephrosis results in impaired renal function due to the scars caused by urinary reflux; this may result in chronic renal failure. Urinary reflux has been known as a risk factor of pyelonephritis; impaired pain sensation in SCI patients hides flank pain as a symptom of pyelonephritis, and this may act as a predisposing factor for developing renal failure in these patients in long term. The prevalence of chronic renal failure was estimated as $4.8 \%$ in the present study. The prevalence of end stage renal disease in general population is estimated to be 1699 in one million individuals (0.17\%) (27). It is clear that a longer duration of SCI as a predisposing factor of renal complication increases the risk of developing chronic renal failure. Furthermore, lack of a caregiver for a patient who is not able to take care of him/herself provides a condition for developing all types of renal complications resulting in chronic renal failure.

Besides the disorders in urination system, about 2.0 to $7 \%$ of SCI patients experience at least one episode of renal stone during 10 years $(3,28)$. Renal stones mainly result from early hypercalciuria after SCI $>200$ milligram in 24 hours) which begins about 4 weeks after SCI, reaching the maximum level after 16 weeks. However, several years after the injury, most of the renal stones are secondary to infections (26). The prevalence of renal stones in the patients of the present study was $5.2 \%$ which is remarkably higher than that of the general population estimated to be $0.4-2$ in 1000 individuals with a life-long risk of $12 \%$ (3). Furthermore, higher risk of developing renal stone in patients with more severe SCI has been attributed to more impaired metabolism of minerals in these individuals (29). Although renal stones smaller than 1 centimeter can be followed without any intervention, about half of the SCI patients with these stones would be symptomatic within 5 years, and about a half of the symptomatic patients would need invasive interventions (3). One way of passing on small stones is to use excessive fluids and take sufficient exercise; however, as the SCI patients poorly get exercise, development of a small stone can act as a nucleus for deposition of other minerals providing conditions for urinary stasis and other renal complications. Moreover, as a result of impaired sensory system in SCI patients the pain resulted from ureteral obstruction is not well sensed by the patients.

To our knowledge, the present study is the largest crosssectional study in Iran evaluating renal and urological 
complication in SCI patients; however, there were several limitations due to the retrospective and cross-sectional nature of the study. Our data base was not able to evaluate the effects of other factors such as underlying diseases, method of bladder management and changes in the methods of bladder management during the past years. However, catheterization method widely varies during the years after SCI and it is difficult to determine a dominant method for each patient. Furthermore, we did not determine the time priority of UTI and renal stone in patients which made us unable to find out the cause and effect relation between these two complications. Since the present study was conducted on the patients under the coverage of State Welfare Organization which mostly has a low socioeconomic state, the findings may not be generalized to patients with higher socioeconomic states. Moreover, the real prevalence of the renal and urological complications might be more or less if the patients omitted from the final analysis due to incomplete data were included. However, according to the large sample size of the study, the results seem considerable. Since some of the studies have assessed the complications in the acute phase after SCI, the present study is of the few studies evaluating the risk factors of developing renal and urological complications during the subsequent years following SCI.

Conclusion: demographic and environmental factors are different among the SCI patients with and without renal and urological complications suggesting their role in the development of these complications. Regarding the higher risk of developing renal and urological complications in SCI patients, more studies are necessary to determine the modifiable factors in patients' lifestyle to design preventive plans to adjust these risk factors.

\section{Acknowledgements}

The authors would like to thank Dr Alireza Khoshdel for his help and support in the study performance. This study was funded by grants from the Research Deputy of AJA University of Medical Sciences, Tehran, Iran

\section{Authors' Contribution}

Banafshe Dormanesh developed the original idea and the protocol, drafted the manuscript, abstracted data, submited the article and guarantor. Mohammad Khak designed the study, analyzed data, helped in writing the article, collected the data, Vafa Rahimimovaghar are study supervisors, material and technical supporters.

\section{Financial Disclosure}

The authors declare that they have no other financial interests.

\section{Funding/Support}

This study was supported in part by the grant No. 68984 from the AJA University.

\section{References}

1. Garcia Leoni ME, Esclarin De Ruz A. Management of urinary tract infection in patients with spinal cord injuries. Clin Microbiol Infect. 2003;9(8):780-5.

2. Rahimi-Movaghar V, Saadat S, Rasouli MR, Ganji S, Ghahramani M, Zarei MR, et al. Prevalence of spinal cord injury in Tehran, Iran.J Spinal Cord Med. 2009;32(4):428-31.

3. Chen Y, DeVivo MJ, Roseman JM. Current trend and risk factors for kidney stones in persons with spinal cord injury: a longitudinal study. Spinal Cord. 2000;38(6):346-53.

4. Taghipoor KD, Arejan RH, Rasouli MR, Saadat S, Moghadam M, Vaccaro AR, et al. Factors associated with pressure ulcers in patients with complete or sensory-only preserved spinal cord injury: is there any difference between traumatic and nontraumatic causes? J Neurosurg Spine. 2009;11(4):438-44.

5. Harvey C, Wilson SE, Greene CG, Berkowitz M, Stripling TE. New estimates of the direct costs of traumatic spinal cord injuries: results of a nationwide survey. Paraplegia.1992;30(12):834-50.

6. Rahimi-Movaghar V, Moradi-Lakeh M, Rasouli MR, Vaccaro AR. Burden of spinal cord injury in Tehran, Iran. Spinal Cord. 2010;48(6):492-7.

7. DeVivo MJ, Black KJ, Stover SL. Causes of death during the first 12 years after spinal cord injury. Arch Phys Med Rehabil. 1993;74(3):248-54.

8. Ost MC, Lee BR. Urolithiasis in patients with spinal cord injuries: risk factors, management, and outcomes. Curr Opin Urol. 2006;16(2):93-9.

9. Fonte N. Urological care of the spinal cord-injured patient. $J$ Wound Ostomy Continence Nurs. 2008;35(3):323-31.

10. Spinal cord injury facts and figures at a glance.J Spinal Cord Med. 2012;35(1):68-9.

11. Bennett E. Intermittent self-catheterisation and the female patient. Nurs Stand. 2002;17(7):37-42.

12. Hooton TM, Scholes D, Stapleton AE, Roberts PL, Winter C, Gupta $\mathrm{K}$, et al. A prospective study of asymptomatic bacteriuria in sexually active young women. $N$ Engl J Med. 2000;343(14):992-7.

13. Nicolle LE. Asymptomatic bacteriuria: when to screen and when to treat. Infect Dis Clin North Am. 2003;17(2):367-94.

14. Nicolle LE. Uncomplicated urinary tract infection in adults including uncomplicated pyelonephritis. Urol Clin North Am. 2008;35(1):1-12.

15. Salvatore S, Cattoni E, Siesto G, Serati M, Sorice P, Torella M. Urinary tract infections in women. Eur J Obstet Gynecol Reprod Biol. 2011;156(2):131-6.

16. Woodford HJ, George J. Diagnosis and management of urinary infections in older people. Clin Med. 2011;11(1):80-3.

17. Benevento BT, Sipski ML. Neurogenic bladder, neurogenic bowel, and sexual dysfunction in people with spinal cord injury. Phys Ther. 2002;82(6):601-12.

18. Krassioukov A, Warburton DE, Teasell R, Eng JJ. A systematic review of the management of autonomic dysreflexia after spinal cord injury. Arch Phys Med Rehabil. 2009;90(4):682-95.

19. Esclarin De Ruz A, Garcia Leoni E, Herruzo Cabrera R. Epidemiology and risk factors for urinary tract infection in patients with spinal cord injury. JUrol. 2000;164(4):1285-9.

20. Stamm WE. Catheter-associated urinary tract infections: epidemiology, pathogenesis, and prevention. Am JMed.1991;91(3B):65S-71S.

21. Cardenas DD, Mayo ME. Bacteriuria with fever after spinal cord injury. Arch Phys Med Rehabil. 1987;68(5 Pt1):291-3.

22. Robinson J. Intermittent self-catheterization: principles and practice. Br J Community Nurs. 2006;11(4):144-6.

23. Heard L, Buhrer R. How do we prevent UTI in people who perform intermittent catheterization? Rehabil Nurs. 2005;30(2):44-5.

24. Foley SJ, McFarlane JP, Shah PJ. Vesico-ureteric reflux in adult patients with spinal injury. Br J Urol.1997;79(6):888-91. 
25. Ku JH, Choi WJ, Lee KY, Jung TY, Lee JK, Park WH, et al. Complications of the upper urinary tract in patients with spinal cord injury: a long-term follow-up study. Urol Res. 2005;33(6):435-9.

26. McKinley WO, Jackson AB, Cardenas DD, DeVivo MJ. Long-term medical complications after traumatic spinal cord injury: a regional model systems analysis. Arch Phys Med Rehabil.1999;80(11):1402-10.

27. Collins AJ, Foley RN, Chavers B, Gilbertson D, Herzog C, Johansen K, et al. 'United States Renal Data System 2011 Annual Data Re- port: Atlas of chronic kidney disease \& end-stage renal disease in the United States. Am J Kidney Dis. 2012;59(1 Suppl 1):A7.

28. DeVivo MJ. Sir Ludwig Guttmann Lecture: trends in spinal cord injury rehabilitation outcomes from model systems in the United States: 1973-2006. Spinal Cord. 2007;45(11):713-21.

29. Oleson CV, Patel PH, Wuermser LA. Influence of season, ethnicity, and chronicity on vitamin D deficiency in traumatic spinal cord injury. J Spinal Cord Med. 2010;33(3):202-13. 